EDITORIAL

\title{
Prostate cancer and prostatic diseases is "Your" journal
}

(c) The Author(s), under exclusive licence to Springer Nature Limited 2022

Prostate Cancer and Prostatic Diseases (2022) 25:3-4; https://doi. org/10.1038/s41391-022-00499-5

\section{Dear Reader,}

It is an honor and a privilege to write this editorial as the new Editor-in-Chief of Prostate Cancer and Prostatic Diseases. In the last 10 years under the leadership of Stephen J Freedland and his editorial board, Prostate Cancer and Prostatic Diseases has become one of the highest ranked urology journals in the world, with an excellent scientific reputation, outstanding journal metrics, and a wide visibility through the nature.com portfolio. Prostate Cancer and Prostatic Diseases is of interest to surgeons, oncologists, clinicians and to those involved in clinical and basic research of prostatic diseases and as the journal is considered a source of innovative research, guidance and discussion. I will be always in debt to Stephen, now Editor Emeritus of Prostate Cancer and Prostatic Diseases, for his friendship and his work on the Journal. As the new editor-inchief of Prostate Cancer and Prostatic Diseases, I will certainly follow the excellent direction started by Stephen and maintain his habit of innovation. However, I would like to evaluate some changes to better interact with the readers and authors, to better understand their unmet needs and offer a journal that can answer their requests. Our era is an era of continuous change as probably are our readers; scientific data are often and easily available on social media (SoMe) and the current and future generation of urologists and scientists will probably appreciate a better SoMe presence of our journal. SoMe plays an important role in the rapid and global information exchange among physicians, patients, organizations and stakeholders in the medical field, and its powerful reach can be involved in the dissemination of evidence-based medicine. For the first time Prostate Cancer and Prostatic Diseases will include an Associate Editor who will be responsible for SoMe. Visibility is an important factor in identifying the right journal and most authors are interested in reaching researchers outside their own field. In this situation, increasing the social visibility of our journal is essential to satisfy the potential author's needs.

The success of a journal is based on the number of readers, subscriptions, authors, and of course reviewers. Our loyal reviewers, without whom the peer review process cannot exist, will be recognized and directly involved in the life of the journal. Online and onsite courses on the principles and practice of medical writing, manuscript refereeing and publishing should attract and train new possible young authors or reviewers. The identification of young colleagues interested in an editorial internship with our journal to gain insights into the editorial process, to contribute to the journal and to understand the editing processes of a peer reviewed journal, also will be encouraged.

Prostate Cancer and Prostatic Diseases is now considered a wellrespected international journal and, in my opinion, the standard reference for investigators of prostatic diseases. Members of the Editorial Board, re-considered on an annual basis, should reflect its international visibility and I need to build a diverse team of worldleading and international multidisciplinary experts. New Consulting Editors, from the five continents, should also act as "ambassadors" for Prostate Cancer and Prostatic Diseases to encourage submissions of novel and important studies from the most important regional and international meetings and researches.

The future of scientific publication is, without any doubt, open access. Prostate Cancer and Prostatic Diseases is a transformative journal and when a manuscript is accepted for publication, authors can choose to publish using either the traditional publishing route, or via immediate Gold Open Access. Almost 30 years ago, Paul Ginsparg, installed a server at the Los Alamos National Laboratory to allow the free access to preprints in physics, starting the Open Access movement. Since then, several scientific, research and library organizations have supported the open access policy and in the last 10 years we have observed a continuous rise of the percentage of Open Access manuscripts reaching about $45 \%$ of all the manuscripts published in clinical medicine in 2018. There is no doubt that Open Access increases visibility, visibility creates citation, citation creates usage and usage creates impact factor. Furthermore, during the Covid-19 pandemic, preprints have been essential for rapid dissemination of new findings, and some researchers feel that if openness of communication is valuable in a time of crisis, it should surely be also fundamental in normal times as well. The numbers of Open Access manuscripts on Prostate Cancer and Prostatic Diseases are increasing but the target has not been reached. Although I know that open access is the present and future of scientific publications, I also know that high-quality publications are the main aim and that proposals from non-funded researchers should not be excluded but conserved in some way.

Following my appointment, I have received so many congratulations from my colleagues, and particularly from other members of the Board, for which I am grateful, but I have quickly realized the tremendous amount of time and effort that I will need to support the journal, to maintain or even increase its values and visibility and to reach my objectives. However, more than ten years ago I was introduced to editorial work as a reviewer of European Urology by Prof Montorsi and I want to end my editorial with one of his statements: I know that I will do my best with passion, completely devoted to the journal and its readers 365 days a year, but I will succeed in my objectives if I can serve the readers and authors of Prostate Cancer and Prostatic Diseases 
and if you, the reader, will consider Prostate Cancer and Prostatic Diseases as "your" journal.

Cosimo De Nunzio

Cosimo De Nunzio iD ${ }^{1 凶}$

${ }^{1}$ Department of Urology, Sant'Andrea Hospital, Sapienza University of Rome, Via di Grottarossa 1035/1039, 00189 Rome, Italy.

凶email: cosimodenunzio@virgilio.it

\section{AUTHOR CONTRIBUTIONS}

CDN has contributed to writing and design of the editorial.

\section{COMPETING INTERESTS}

The author declares no competing interests.

\section{ADDITIONAL INFORMATION}

Correspondence and requests for materials should be addressed to Cosimo De Nunzio.

Reprints and permission information is available at http://www.nature.com/ reprints

Publisher's note Springer Nature remains neutral with regard to jurisdictional claims in published maps and institutional affiliations. 